
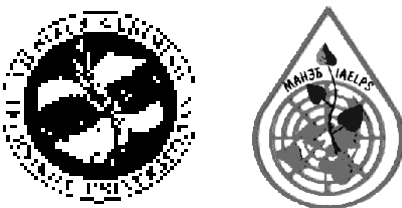

\title{
ЭКОЛОГИЧЕСКАЯ БЕЗОПАСНОСТЬ В УСЛОВИЯХ РАДИАЦИОННЫХ АВАРИЙ. АНАЛИЗ И ОЦЕНКА АВАРИЙНЫХ СИТУАЦИЙ НА РАДИАЦИОННО ОПАСНЫХ ОБЪЕКТАХ
}

\author{
С. В. Косырев, И. А. Матысик, И. В. Свитнев \\ Получено 01.03.2005; принято 14.03.2005
}

\begin{abstract}
Аннотация. Риск радиационной аварии на радиационно опасных объектах (РОО) сводится к минимуму в том случае, если техническими и организационными мероприятиями обеспечивается непревышение установленных доз по внутреннему и внешнему облучению персонала и населения, а также норм по содержанию радиоактивных продуктов в окружающей среде при нормальной эксплуатации и проектных авариях. На наш взгляд, в регионах, потенциально подверженных радиационным нагрузкам, серьезное внимание должно быть уделено обеспечению безопасности РОО в условиях аварий или аварийных ситуаций. Анализ состояния ядерной и радиационной безопасности в условиях аварий осуществлен на примере РОО Архангельской области. На основе анализа 23 POО произведена идентификация особо опасных в экологическом отношении радиационных объектов. В связи с этим разработана методика оценки экологической обстановки района в результате аварийной ситуации на РОО. На первом этапе методики производится идентификация особо опасных радиационных объектов и моделируется воздействие радиационной нагрузки на исследуемый регион (район). На втором этапе производится анализ и оценка аварийных ситуаций на РОО.
\end{abstract}

Ключевые слова: радиационно опасные объекты, авария, внутреннее и внешнее облучение, ядерная и радиационная безопасность.

\section{ECOLOGICAL SAFETY DURING RADIOLOGICAL ACCIDENTS. ANALYSIS AND EVALUATION OF EMERGENCY SITUATIONS AT RADIOLOGICALLY DANGEROUS OBJECTS}

\author{
S. V. Kosyrev, I. A. Matysik, I. V. Svitnev \\ Received 1 Mar 2005; accepted 14 Mar 2005
}

\begin{abstract}
The risk of radiological accidents at dangerous objects is minimal when with the help of technical and organizational means it is guaranteed that indoor and outdoor radiation doses are not exceeded. Also, it is necessary to ensure that the quantity of radiological products in the environment doesn't exceed allowed levels both at a normal exploitation of an object and during an accident. In regions with high radiological loads it is necessary to pay enough attention to the safety of dangerous objects in the situations of accidents. An example given in the paper on how to deal with accidents is based on a situation in the Archangelsk region. Analysis was implemented at 23 radiologically dangerous objects. The results of the analysis allowed to determine objects that are dangerous in an ecological sense. Relying on that, methodology of evaluating the situation in the region was created. The main thing is that evaluation of an ecological situation is judged relying on an emergency situation at a radiologically dangerous object.

The first step of the methodology preparation is identification of particularly dangerous objects, and modeling of radiological load on an investigated area. The second step of the work is to review the second stage of the methodology which would be dedicated to the analysis and evaluation of emergency situations at radiologically dangerous objects.
\end{abstract}

Keywords: radiologically dangerous objects, accident, indoor and outdoor radiation, nuclear and radiological safety. 


\section{1. Введение}

Риск радиационной аварии на радиационно опасных объектах (РОО) сводится к минимуму в том случае, если техническими и организационными мероприятиями обеспечивается непревышение установленных доз по внутреннему и внешнему облучению персонала и населения, а также норм по содержанию радиоактивных продуктов в окружающей среде при нормальной эксплуатации и проектных авариях.

Для этого предусматриваются следующие этапы обеспечения безопасности:

1) обеспечение безопасности при нормальной эксплуатации;

2) предотвращение аварий;

3) обеспечение безопасности в условиях аварий.

На наш взгляд, в регионах, потенциально подверженных радиационным нагрузкам, серьезное внимание должно быть уделено обеспечению безопасности РОО в условиях аварий или аварийных ситуаций.

\section{2. Анализ состояния ядерной и радиационной безопасности в условиях аварий}

Анализ состояния ядерной и радиационной безопасности в условиях аварий осуществлен на примере РОО Архангельской области. На основе анализа 23 РОО произведена идентификация особо опасных в экологическом отношении радиационных объектов. В связи с этим разработана методика оценки экологической обстановки района в результате аварийной ситуации на РОО.

На первом этапе методики производится идентификация особо опасных радиационных объектов и моделируется воздействие радиационной нагрузки на исследуемый регион (район).

В настоящей работе рассматривается второй этап методики, согласно которому производится анализ и оценка аварийных ситуаций на РОО. На основе предварительного анализа аварий на РОО Архангельской области предложена «Сводная таблица аварийных ситуаций», в которой рассматривается пять наиболее опасных аварийных ситуаций. Оценка аварийных ситуаций производится на основании вероятностного подхода. При этом учитывается разнородность источников радиационной опасности, их потенциальная опасность и степень изученности.

Произведена вероятностная оценка аварийных ситуаций на ряде исследуемых объектов.

1. Оценен риск радиационной аварии с неуправляемым радиоактивным выбросом на Кольской АЭС, определенный на основе статистических данных и составляющий $10^{-71 /}$ год.

2. Произведена вероятностная оценка аварийной ситуации на грузовых судах с радиоактивными веществами на борту предприятий «Севморпароходства» и «Архморторгпорта», осуществленная на основе биноминального распределения.

Известно, что предприятия лицензированы в отношении обращения с радиоактивными веществами, однако их транспортировка не осуществляется из-за отсутствия договоров по их перевозке.

Исходя из этого, предприятие рассматривается как система, критическим элементом которой при аварийной ситуации с радиоактивными веществами являются грузовые суда, которые представляют собой $n$ независимых элементов, функционирующих на определенном интервале пространства, причем вероятность отказа $q$ отдельного элемента (судна) на этом интервале составляет $8,7 \times 10^{-6}$ на 1600 км.

В этом случае число отказавших элементов $k$ (аварийных судов) за рассмотренный интервал будет описываться биноминальным распределением, и вероятность аварии грузовых судов с радиоактивными веществами на борту $P(k)$ определяется согласно биноминальному распределению.

3. На основе анализа деятельности радиационно опасных предприятий г. Северодвинска за 2004 г. выявлено количество исходных событий (причины аварий) и произведен подсчет интенсивности события в год.

Опыт работы предприятий до аварийной ситуации показывает, что интенсивность отказов $q(t)$ как функция «наработки» определенного этапа эксплуатации имеет вид экспоненциальной кривой (см. рис.).

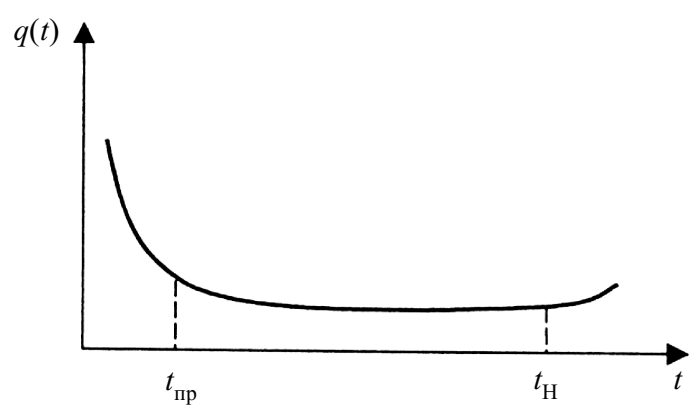

Функция „наработки“

Из графика видно, что весь интервал работы предприятия (этапа эксплуатации) может быть разбит на три периода:

$\left(0, t_{\text {пр }}\right)-$ начальный период эксплуатации предприятия;

$\left(t_{\text {пр, }} t_{\mathrm{H}}\right)$ - период нормальной работы предприятия, характеризующийся наиболее низким уровнем интенсивности отказов и сохраняющийся приблизительно постоянным в течение периода нормальной работы; 
$\left(t>t_{\mathrm{H}}\right)-$ период старения, связанный с заменой изношенного оборудования.

В период нормальной работы предприятия моделью для описания вероятности аварийной ситуации, возникающей в результате исходных событий (причин аварии), является экспоненциальное распределение.

4. Анализ деятельности авиакомпаний региона по транспортировке радиоактивных отходов позволил сделать следующие выводы:

- падение самолета с радиоактивными веществами на борту возможно лишь в результате целенаправленного террористического акта;

- вероятность поражения объекта зависит от массы транспортируемого радиоактивного вещества (мощности источника) и точности доставки самолета к цели.

\section{Литература}

1. Бахметьев, А. М.; Самойлов, О. Б.; Кусынин, Г. Б. Методы оценки и обеспечения безопасности ЯЭУ. Москва: Энергоатомиздат, 1988.

2. Измалков, В. И. Методология системного анализа источников радиационной опасности, прогнозирования и оценка радиационной обстановки и уровней риска. СПб, 1994.

\section{APLINKOS APSAUGA RADIACINĖS AVARIJOS ATVEJU. AVARINIŲ SITUACIJŲ PAVOJINGUOSE OBJEKTUOSE ANALIZE் IR IVERTINIMAS}

\section{S. V. Kosyrev, I. A. Matysik, I. V. Svitnev}

\section{$\mathrm{S}$ a n tra u k a}

Avariju pasekmių rizika radiacijos požiūriu pavojinguose objektuose mažiausia tuo atveju, kai techninèmis bei organizacinėmis priemonėmis yra užtikrinama, kad objekto personalo ir aplinkiniu gyventojų vidinès ir išorinès apšvitos dozės nebūtų viršijamos. Taip pat būtina stebėti, kad eksploatuojant tokị objektą ir numatytais jo avarijų atvejais radioaktyviujų medžiagų kiekis aplinkoje neviršytų normų. Didelès radiacinès apkrovos regionuose būtina itin daug dėmesio skirti saugumui užtikrinti avarijų bei avarinių situacijų atveju. Analizė atlikta remiantis Archangelsko regiono pavyzdžiu. Išanalizavus 23 tuo atžvilgiu pavojingus objektus, buvo nustatyti ekologijos požiūriu ypač pavojingi. Sukurta metodika ekologinei situacijai ịvertinti.

Pirmuoju darbo etapu identifikuojami ypač pavojingi radiacijos požiūriu objektai, sumodeliuojama nagrinèjamo regiono radiacinė apkrova. Antrasis darbo etapas - pavojingų objektų avarinių situacijų analizės ir ịvertinimo radiacijos požiūriu metodikos tobulinimas.

Raktažodžiai: radiacijos požiūriu pavojingi objektai, avarija, išorinė ir vidinè apšvita, branduolinė ir radiacinė sauga. 